\title{
Atypical Clival Fracture Due to Minor Trauma and Cerebrospinal Fluid Rhinorrhea
}

\author{
Hajime Ono
}

Key words: clival bone fracture, endoscopic surgery

(Intern Med 56: 1757, 2017)

(DOI: 10.2169/internalmedicine.56.8744)

In some previous cases of clival bone fracture in patients with severe head injury, the diagnosis of clival bone fracture was relatively complicated. Regarding the incidence of clival fractures, some reports have shown an incidence of between $0.21 \%$ and $1.2 \%$ among traumatic brain injury victims who are admitted to hospital (1-3). The relationship between the site of the head and the type of fracture is well described in previous reports. The majority of clival bone fractures appear as linear fractures on CT and can be classified into three types: longitudinal, transverse and oblique (4). However, there are fractures that do not display the typical fracture pattern. Tohge et al. showed a case of an atypical clival fracture in a 38-year-old man with a history of head trauma (5). The clival bone fractures appeared as a roundshaped defect, and no continuous linear fracture was recognized on CT. The relationship between traumatic force and clival bone fractures is very interesting. In the previously mentioned case, the atypical fracture shape cannot be explained by osteoporosis, because the patient was young. In many reported cases, the main mechanism was occipital trauma (6), which fractured the low-resistance floor of the anterior skull base, due to the combined effect of osseous and cerebral oscillations-causing a pressure gradient inside the skull. Atypical bone injury is considered to be related to the state of the clival bone, including the development of a well-pneumatized sphenoid sinus. On the other hand, some reports describe cerebrospinal fluid (CSF) rhinorrhea and subsequent bacterial meningitis as a result of clival bone fracture. In previous reports, CSF occurred in $7.7 \%$ of pa- tients with clival fractures (3). Endoscopic nasal surgical procedures have been developed for the treatment of CSF leakage, and this endoscopic repair method is considered a reliable technique for achieving fistula closure.

The author states that he has no Conflict of Interest (COI).

\section{References}

1. Corradino G, Wolf AL, Mirvis S, Joslyn J. Fractures of the clivus: classification and clinical features. Neurosurgery 27: 592-596, 1990.

2. Ochalski PG, Spiro RM, Fabio A, Kassam AB, Okonkwo DO. Fractures of the clivus: a contemporary series in the computed tomography era. Neurosurgery 65: 1063-1069, 2009.

3. Winkler-Schwartz A, Correa JA, Marcoux J. Clival fractures in a level I trauma center. J Neurosurg 122: 227-235, 2015.

4. Meguro K, Rowed DW. Traumatic aneurysm of the posterior inferior cerebellar artery caused by fracture of the clivus. Neurosurgery 16: 666-668, 1985.

5. Tohge R, Takahashi M. Cerebrospinal Fluid Rhinorrhea and Subsequent Bacterial Meningitis due to Atypical Clival Fracture. Intern Med 56: 1911-1914, 2017.

6. Ono H, Uchida M, Tanaka Y, Tanaka K, Hashimoto T. Traumatic longitudinal clival fracture in a child - case report. Neurol Med Chir (Tokyo) 51: 707-710, 2011.

The Internal Medicine is an Open Access article distributed under the Creative Commons Attribution-NonCommercial-NoDerivatives 4.0 International License. To view the details of this license, please visit (https://creativecommons.org/licenses/ by-nc-nd/4.0/).

Department of Neurosurgery, St. Marianna University School of Medicine, Toyoko Hospital, Japan

Received for publication December 21, 2016; Accepted for publication January 5, 2017

Correspondence to Dr. Hajime Ono, gen21@marianna-u.ac.jp

(C) 2017 The Japanese Society of Internal Medicine Journal Website: http://www.naika.or.jp/imonline/index.html 